\title{
Potential Evapotranspiration Reduction and Its Influence on Crop Yield in the North China Plain in 1961-2014
}

\author{
Wanlin Dong $\mathbb{D}^{1,2}$ Chao Li, ${ }^{3}$ Qi Hu, ${ }^{4}$ Feifei Pan, ${ }^{5}$ Jyoti Bhandari $\mathbb{D}^{2},{ }^{2}$ and Zhigang Sun $\mathbb{D}^{2,6}$ \\ ${ }^{1}$ China Meteorological Administration Training Centre, Beijing 100081, China \\ ${ }^{2}$ Key Laboratory of Ecosystem Network Observation and Modeling, \\ Institute of Geographic Sciences and Natural Resources Research, Chinese Academy of Sciences, Beijing 100101, China \\ ${ }^{3}$ Mentougou Meteorological Service, Beijing 102308, China \\ ${ }^{4}$ College of Resources and Environmental Sciences, China Agricultural University, Beijing 100193, China \\ ${ }^{5}$ Department of Geography, University of North Texas, Denton, TX 76203, USA \\ ${ }^{6}$ College of Resources and Environment, University of Chinese Academy of Sciences, Beijing 100190, China
}

Correspondence should be addressed to Zhigang Sun; sun.zhigang@igsnrr.ac.cn

Received 10 June 2019; Accepted 23 December 2019; Published 16 March 2020

Guest Editor: Salman Tariq

Copyright ( 12020 Wanlin Dong et al. This is an open access article distributed under the Creative Commons Attribution License, which permits unrestricted use, distribution, and reproduction in any medium, provided the original work is properly cited.

\begin{abstract}
Climate change has caused uneven changes in hydrological processes (precipitation and evapotranspiration) on a space-temporal scale, which would influence climate types, eventually impact agricultural production. Based on data from 61 meteorological stations from 1961 to 2014 in the North China Plain (NCP), the spatiotemporal characteristics of climate variables, such as humidity index, precipitation, and potential evapotranspiration $\left(\mathrm{ET}_{0}\right)$, were analyzed. The sensitivity coefficients and contribution rates were applied to $\mathrm{ET}_{0}$. The NCP has experienced a semiarid to humid climate from north to south due to the significant decline of $\mathrm{ET}_{0}\left(-13.8 \mathrm{~mm}\right.$ decade $\left.{ }^{-1}\right)$. In the study region, $71.0 \%$ of the sites showed a "pan evaporation paradox" phenomenon. Relative humidity had the most negative influence on $\mathrm{ET}_{0}$, while wind speed, sunshine hours, and air temperature had a positive effect on $\mathrm{ET}_{0}$. Wind speed and sunshine hours contributed the most to the spatiotemporal variation of $\mathrm{ET}_{0}$, followed by relative humidity and air temperature. Overall, the key climate factor impacting $\mathrm{ET}_{0}$ was wind speed decline in the NCP, particularly in Beijing and Tianjin. The crop yield in Shandong and Henan provinces was higher than that in the other regions with a higher humidity index. The lower the humidity index in Hebei province, the lower the crop yield. Therefore, potential water shortages and water conflict should be considered in the future because of spatiotemporal humidity variations in the NCP.
\end{abstract}

\section{Introduction}

Hydrological processes and crop water requirements have been modified by climate change on local, regional, and global scales $[1,2]$. The modification of climate change has coincided with surface air temperature increase.

In the hydrological cycle, actual evapotranspiration (ET) and potential evapotranspiration $\left(\mathrm{ET}_{0}\right)$ played important roles [3], particularly in soil evaporation and crop transpiration, eventually impact crop productivity. ET is measured as the quantity of water evaporating from an area under existing atmospheric conditions [4]. ET is controlled by two processes occurring simultaneously: evaporation from the soil and transpiration from the leaf surface [5]. $\mathrm{ET}_{0}$ is calculated as the maximum quantity of water that can be lost as water vapor in a given climate, by a continuous, extensive stretch of vegetation covering the ground when there is no shortage of water [6]. $\mathrm{ET}_{0}$ is determined by the meteorological conditions and the surface type [7]. Because $\mathrm{ET}_{0}$ is computed from precipitation, temperature, relative humidity, wind speed, and sunshine hours [8-10], any change in these variables is likely to change the $\mathrm{ET}_{0}$. Furthermore, these changes created more benign or stressful conditions for $\mathrm{ET}_{0}[11,12]$. $\mathrm{ET}_{0}$ had a significant impact on the availability of water resources [13], consequently influencing agricultural productivity. Plant growth planning 
often requires information on $\mathrm{ET}_{0}[14,15]$ to estimate crop transpiration. Therefore, the study of $\mathrm{ET}_{0}$ under climate change has become an interesting research issue to scientists around the world. Also, it is important to identify the changes in $\mathrm{ET}_{0}$ on a regional scale.

The humidity index $(K)$, change in precipitation, and $\mathrm{ET}_{0}$ were applied to estimate dry-wet variations. Previous research studies on climate type only considered the influence of temperature and precipitation [16, 17] without including the influence of relative humidity, solar radiation, wind speed, and sunshine hours. Therefore, to understand the changing characteristics of climate variations, it is important to integrate water resource management. Furthermore, $K$ can be applied to predict model scenarios that would persist in critical agricultural areas. Therefore, assessing $\mathrm{ET}_{0}$ and $K$ distribution would explain the relationships between climate change and hydrological processes. This would lead to reasonable water regulation and management to maintain the ecohydrological system.

In the NCP, summer maize (Zea mays L.) represents 33\% of the national grain yield, while winter wheat represents $50 \%$ of the national grain yield [18]. Increasing temperature and decreasing precipitation are likely to reduce the yields of several primary crops over the next two decades [19]. Water shortage would be aggravated in the main grain production belt of North China [20, 21]. Bergamaschi et al. [22] indicated that crop yields would reduce by $10-20 \%$ up to 2050 because of warming and drying. Hence, understanding the hydrological distribution in these regions is critical for managing agricultural water resources and adjusting the planting pattern.

At present, there are few studies on the spatiotemporal variations in climate type by integrating the input (precipitation) and output (evapotranspiration) of atmospheric water vapor in the NCP. Therefore, the objectives of this study were to (1) quantify the changes in spatial and temporal variations in $\mathrm{ET}_{0}$ and $K$ in the NCP from 1961 to 2014, (2) quantitatively explain the reasons for the changes in $\mathrm{ET}_{0}$ by analyzing the sensitivity coefficients and contribution rates, and (3) analyse the relationship between $\mathrm{ET}_{0}$ and the crop yield. The results might be useful to agricultural planning and layout.

\section{Materials and Methods}

2.1. Study Area and Data. The study area, located in the NCP $\left(31-43^{\circ} \mathrm{N}\right.$ and $\left.110-123^{\circ} \mathrm{E}\right)$, has a warm, temperate monsoon climate. The precipitation changes significantly in summer. The main crops are summer maize and winter wheat. The mean annual temperature and average annual precipitation were $13.0^{\circ} \mathrm{C}$ and $586 \mathrm{~mm}$, respectively [23]. The soil has a silt-loam texture in the cultivated layer in general. This study was based in Beijing, Tianjin, Hebei province, Henan province, and Shandong province.

In this study, daily meteorological data from January 1961 to December 2014 were obtained from 60 stations in the NCP (Table 1). These data contained daily mean, minimum and maximum temperature, sunshine hours, wind speed, precipitation, and relative humidity provided by the
National Climatic Centre of China Meteorological Administration (http://cdc.cma.gov.cn). The wind speed at $10 \mathrm{~m}$ height was converted to wind speed at $2 \mathrm{~m}$ height using the wind profile relationship introduced in Allen et al. [24], as shown in equation (1). The observed dataset has been subjected to strict quality and homogenization control. The geographical location of the stations is shown in Figure 1.

$$
u_{2}=u_{z} \frac{4.87}{\operatorname{In}(67.8 z-5.42)}
$$

where $u_{2}$ is the wind speed at $2 \mathrm{~m}$ above the ground surface $\left(\mathrm{m} \cdot \mathrm{s}^{-1}\right), u_{\mathrm{z}}$ is the wind speed at $z \mathrm{~m}$ above the surface $\left(\mathrm{m} \cdot \mathrm{s}^{-1}\right)$, and $z$ is the height of measurement above the ground surface (m).

\subsection{Data Analyses}

2.2.1. Estimation of Humidity Index (K). Humidity index is the ratio of precipitation to potential evapotranspiration and is calculated by

$$
K=\frac{P}{\mathrm{ET}_{0}}
$$

where $P$ is the daily precipitation $\left(\mathrm{mm} \cdot \mathrm{d}^{-1}\right)$ and $\mathrm{ET}_{0}$ is the daily potential evapotranspiration $\left(\mathrm{mm} \cdot \mathrm{d}^{-1}\right)$. The classification of climate region based on humidity index is listed in Table 2 [25].

$\mathrm{ET}_{0}$ is calculated by the Penman-Monteith formula [24]:

$$
\mathrm{ET}_{0}=\frac{0.408\left(R_{n}-\mathrm{G}\right)+\gamma 900 / T+273 U_{2}\left(e_{s}-\mathrm{e}_{\mathrm{a}}\right)}{\Delta+\gamma\left(1+0.34 U_{2}\right)},
$$

where $R_{\mathrm{n}}$ is the net radiation at the surface, $\mathrm{MJ} \cdot \mathrm{m}^{-2} \cdot \mathrm{d}^{-1}, G$ is soil heat flux density, $\mathrm{MJ} \cdot \mathrm{m}^{-2} \cdot \mathrm{d}^{-1}$, $\gamma$ is the psychrometric constant, $\mathrm{kPa}{ }^{\circ} \mathrm{C}^{-1}, T$ is the mean daily air temperature, ${ }^{\circ} \mathrm{C}$, $U_{2}$ is the wind speed at a height of $2 \mathrm{~m}, \mathrm{~m} \cdot \mathrm{s}^{-1}, e_{\mathrm{s}}$ is the saturation vapor pressure, $\mathrm{kPa}, e_{\mathrm{a}}$ is the actual vapor pressure, $\mathrm{kPa}$, and $\Delta$ is the slope of the saturated water-vapor pressure curve, $\mathrm{kPa}{ }^{\circ} \mathrm{C}^{-1}$. The computation of all data required for calculating $\mathrm{ET}_{0}$ followed the method and procedure given in Chapter 3 of FAO-56 [24].

2.2.2. Sensitivity Analysis and Sensitivity Coefficient. Sensitivity analysis of the $\mathrm{ET}_{0}$ equation is an effective way to analyze the effect of meteorological factors on $\mathrm{ET}_{0}$ [26]. Previous studies showed the usage of nondimensional relative sensitivity coefficients to explain climate variables influence on $\mathrm{ET}_{0}$ [27]:

$$
S_{V_{i}}=\lim _{\Delta V_{i} \longrightarrow 0}=\left(\frac{\left(\Delta \mathrm{ET}_{0} / \mathrm{ET}_{0}\right)}{\left(\Delta V_{i} / V\right)}\right)=\frac{\partial \mathrm{ET}_{0}}{\partial V_{i}} \frac{V_{i}}{\mathrm{ET}_{0}},
$$

where $S_{V i}$ is the sensitivity coefficient of the $i$ th climate variable, $\mathrm{ET}_{0}$ is the potential evapotranspiration, $\mathrm{mm} \cdot \mathrm{d}^{-1}$, $\Delta \mathrm{ET}_{0}$ is the daily change of $\mathrm{ET}_{0}, V_{i}$ is the $i$ th climate variable, and $\Delta V_{i}$ is the change of $V_{i}$. A positive/negative $S_{V i}$ of a variable indicated that $\mathrm{ET}_{0}$ would increase/decrease as climate variables. The greater the $S_{V i}$, the greater effect of the climate factor on $\mathrm{ET}_{0}$. 
TABLE 1: Geographic characteristic information of each meteorological station in the study.

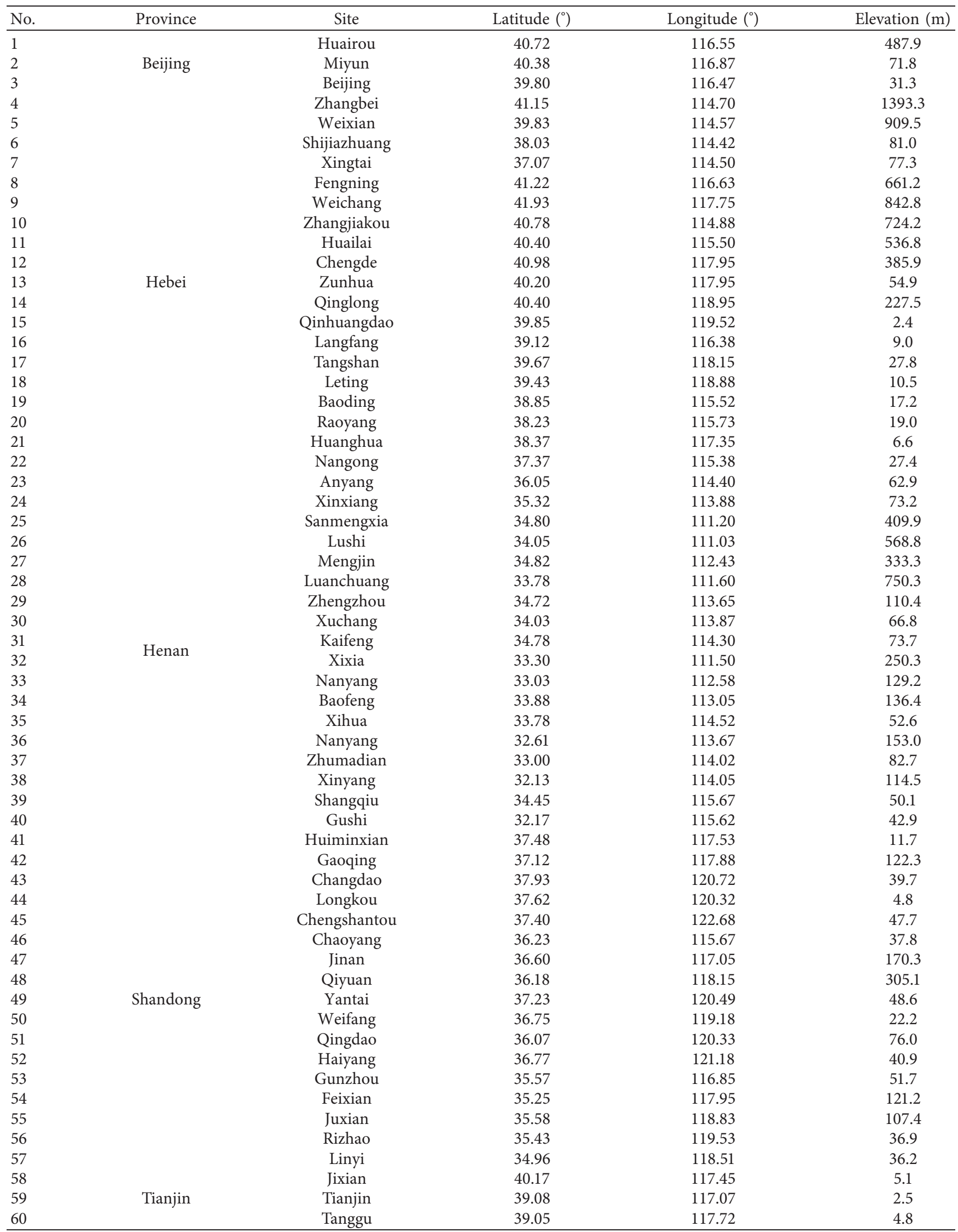




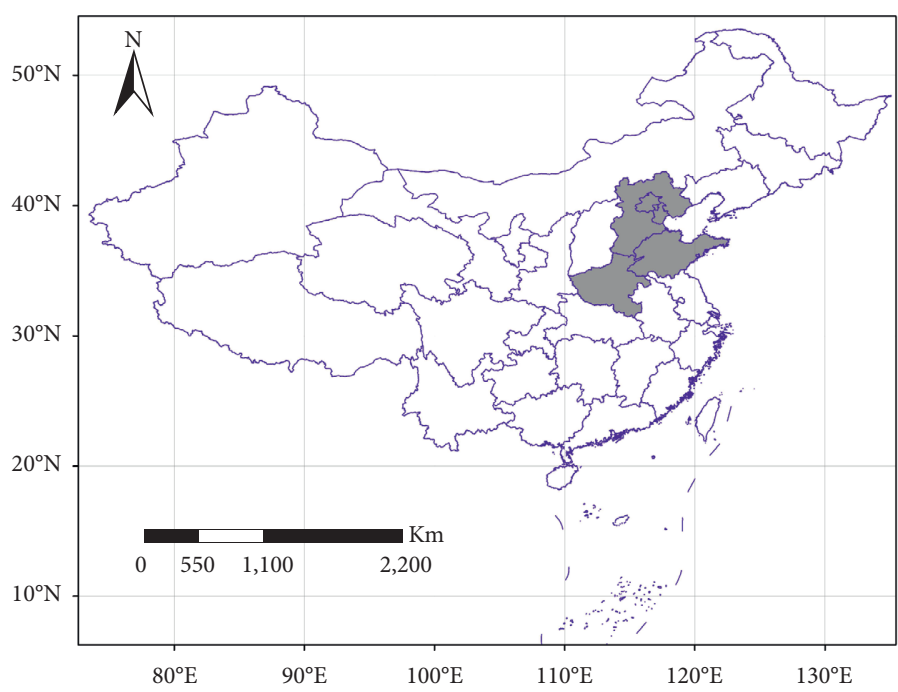

(a)

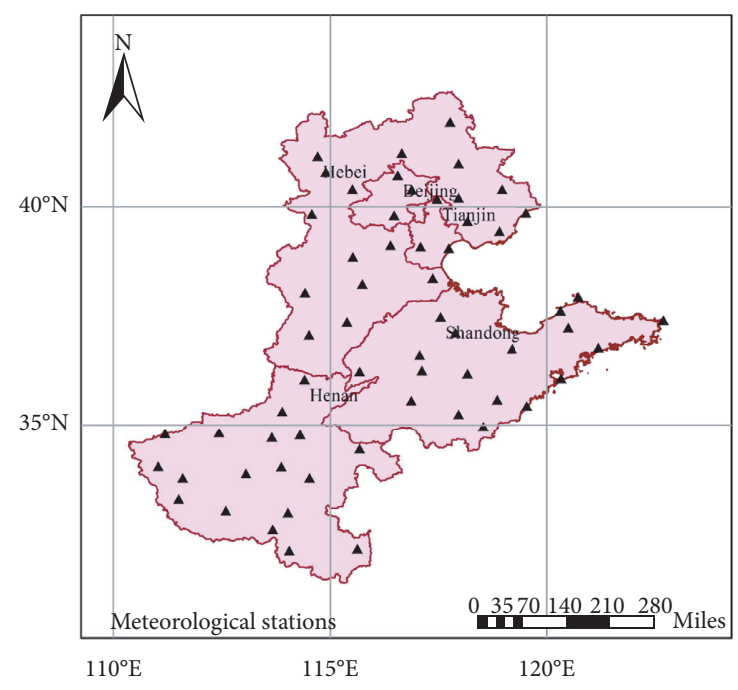

(b)

FIgURE 1: Distribution of meteorological stations in China (a) and the study area (b).

Table 2: Humidity index $(K)$.

\begin{tabular}{lc}
\hline Humidity index & Climate region \\
\hline$K<0.03$ & Extremely arid climate region \\
$0.03 K<0.2$ & Arid climate region \\
$0.2 K<0.5$ & Semiarid climate region \\
$0.5 K<1.0$ & Semihumid climate region \\
$K>1.0$ & Humid climate region \\
\hline
\end{tabular}

2.2.3. Calculation of Attribution Rate. The attribution rate $G_{v i}$ is used to link the climate variable to $\mathrm{ET}_{0}$ :

$$
G_{v i}=S_{v i} \times R_{v i}
$$

where $G_{v i}$ is the contribution of the $i$ th climate variable to $\mathrm{ET}_{0}, S_{v i}$ is the sensitivity coefficient, and $R_{v i}$ is the relative change rate for the $i$ th climate variation, which was given by equation (5). The meaning of $G_{v i}$ is the same as $S_{v i}$.

In this study, $S_{v i}$ and $G_{v i}$ for daily air temperature, solar radiation, relative humidity, and wind speed were estimated to quantify the contribution of each factor to the variation of $\mathrm{ET}_{0}$.

$$
R_{V i}=\frac{\Delta V i}{\bar{V} i}=\frac{n \times \operatorname{Trend}_{V i}}{\bar{V} i}
$$

where Trend $d_{V i}$ is the climate tendency rate for the $i$ th climate variation and is calculated by equation (6), $\overline{V_{i}}$ is the mean value for the climate variation, and $n$ is the time in years. In this study, $n=54$.

2.2.4. Climate Trend. Climate tendency rate $\left(\operatorname{Trend}_{V i}\right)$ was calculated by the least square method:

$$
X_{i}=a t+b, \quad(t=1,2,3 \ldots n),
$$

where $X_{i}$ is the $i$ th climate variation, $t$ is the time in years, a is the regression coefficient, $10 \times a$ is the climate tendency rate, and $b$ is the constant parameter.

\section{Results}

3.1. Annual and Spatial Variation and Tendency of Humidity Index. The humidity index $(K)$ showed an upward trend from north to south, changing from 0.34 to 1.20 (Figure 2(a)), which indicated that the climate of the region varied from semiarid to humid from north to south. The climate in Northwest and mid-west Hebei was semiarid, while that in South Henan was humid, with $K$ above 1 . The other regions had semihumid climate, with $K$ ranging from 0.5 to 1.0 .

The tendency rate of $K$ was -0.005 decade $^{-1}(P=0.63)$, which showed a slight drying trend from south to north (Figure 2(b)). Thirty-five percent of the sites (total $=60$ ) mainly distributed in southern NCP had a tendency rate of $K$ above 0 , which indicated that these regions were wet. The other sites with a tendency rate of $K$ below 0, especially East Shandong and North Hebei, were dry with a tendency rate of $K$ below -0.01 decade $^{-1}$.

3.2. Interdecadal Changes in Precipitation and $E T_{0}$. The tendency rate of precipitation was $-12.4 \mathrm{~mm} \mathrm{decade}{ }^{-1}$, which indicated a downward trend of precipitation. The abrupt decline in precipitation tendency rate was mainly observed in Southeast Hebei and Southeast Shandong (Figure 3(a)). Only $10.0 \%$ of all the sites had a tendency rate of precipitation over 0 .

The $\mathrm{ET}_{0}$ tendency rate was $-13.5 \mathrm{~mm}$ decade $^{-1}$ (Figure 3(b)), which showed a downward trend from 1961 to 2014. The $\mathrm{ET}_{0}$ tendency rate was significant at the 0.05 level in $71.0 \%$ of the sites, especially in mid-east Hebei and midsouth Shandong.

3.3. Sensitivity Coefficient of Temperature $\left(S_{T}\right)$, Relative Humidity $\left(S_{R H}\right)$, Sunshine Hours $\left(S_{S H}\right)$, and Wind Speed $\left(S_{W S}\right)$ to $E T_{0}$ on Annual and Spatial Scales. $S_{\mathrm{T}}$ varied from 0 to 0.15 


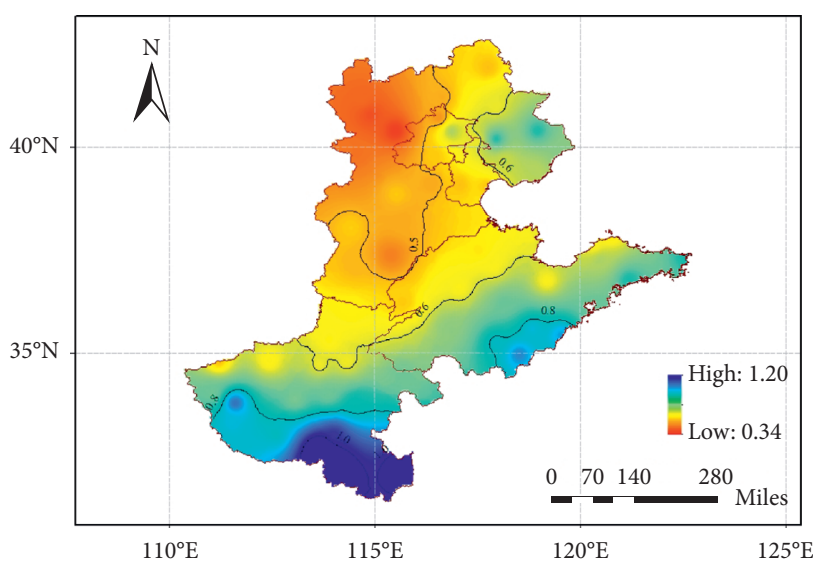

(a)

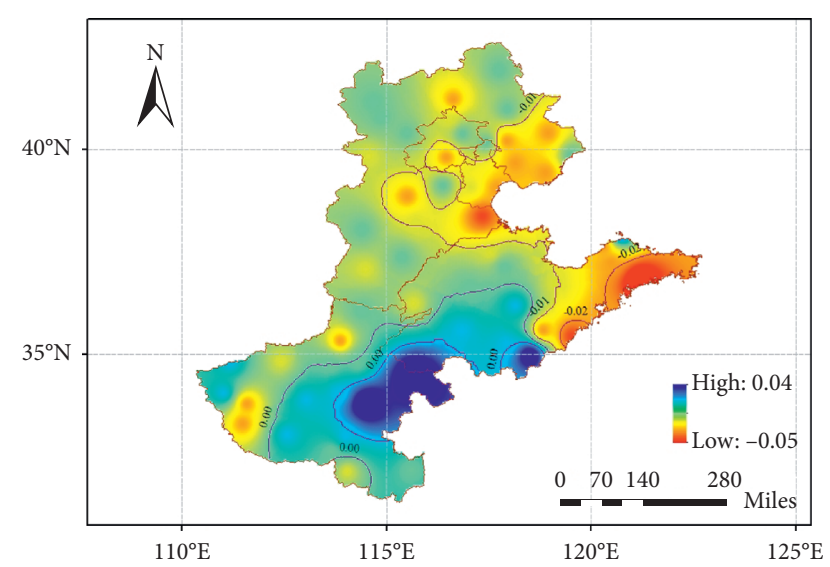

(b)

FIgURE 2: Spatial distribution of humidity index (a) and the tendency rate of humidity index (b) from 1961 to 2014.

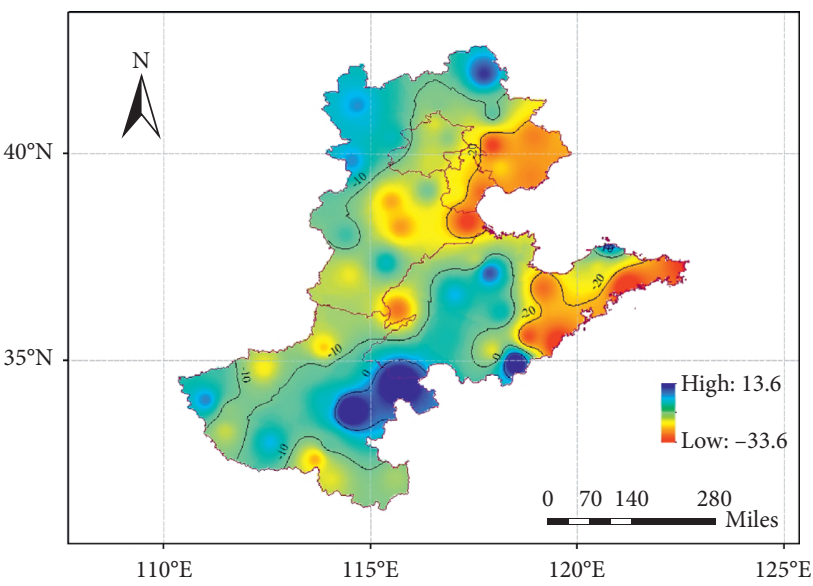

(a)

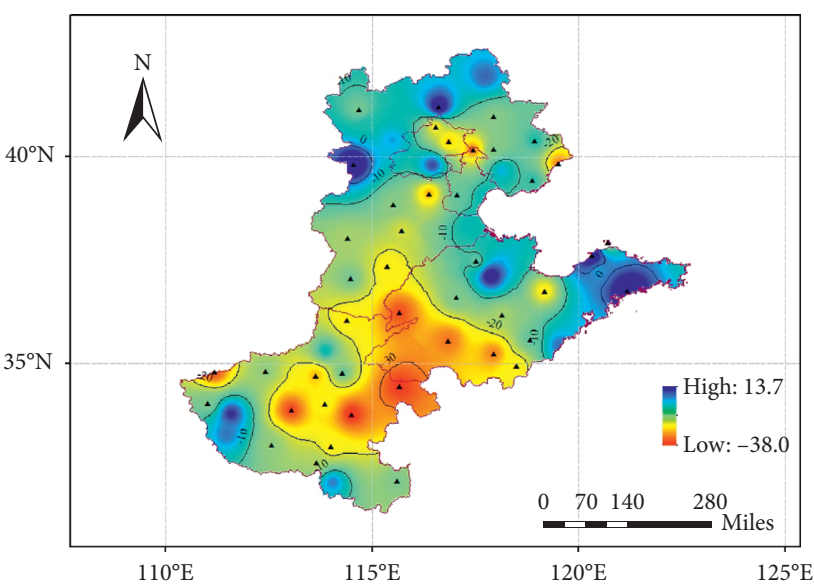

(b)

FIgURE 3: Spatial distribution of precipitation (a) and $\mathrm{ET}_{0}$ (b) tendency rate from 1961 to 2014.

(Figure 4(a)), which meant that $\mathrm{ET}_{0}$ increased with temperature. $S_{\mathrm{T}}$ in the southeast was higher, especially in the Henan province, while it peaked in the mid-region, such as North Shandong, Beijing, Tianjin, and North Hebei. $S_{\mathrm{RH}}$ varied from -0.70 to -0.19 (Figure $4(\mathrm{~b})$ ), which indicated that $\mathrm{ET}_{0}$ decreased as the relative humidity increased. The spatial distribution of $S_{\mathrm{RH}}$ showed a downward trend from south to east. The $S_{\mathrm{RH}}$ was higher in East Shandong, with an absolute value above 0.5. In South Hebei and Beijing, the absolute value of $S_{\mathrm{RH}}$ was below 0.4 . The $S_{\mathrm{SH}}$ in all regions was above 0 , with a mean value of 0.18 (Figure $4(\mathrm{c})$ ). The $S_{\mathrm{SH}}$ showed an upward trend from north to south. $S_{\mathrm{WS}}$ ranged from 0.10 to 0.31 (Figure $4(\mathrm{~d})$ ) and showed a downward trend from north to south. The $S_{\mathrm{WS}}$ in the northern part of the region, e.g., North Hebei, Beijing, and Tianjin, was above 0.21, while in South Henan, it was below 0.18 .

3.4. Climate Factor Attribution Rate to $E T_{0}$ on Annual and Spatial Scales. $G_{v i}$ was applied in this study to indicate the relative change in $\mathrm{ET}_{0}$ resulting from each meteorological factor. The attribution rate of air temperature to $\mathrm{ET}_{0}\left(G_{\mathrm{vT}}\right)$ ranged from $-0.5 \%$ to $4.0 \%$ (Figure $5(\mathrm{a})$ ). $G_{\mathrm{vT}}$ in the northern and eastern parts of the NCP was over 1\%, while it was less than $1 \%$ in the other regions. The attribution rate of relative humidity to $\mathrm{ET}_{0}\left(G_{\mathrm{vRH}}\right)$ ranged from-4.7\% to $10.1 \%$ (Figure 5(b)). $G_{\mathrm{vRH}}$ in North Hebei and Southwest Shangdong was below 0 . The attribution rate of sunshine hours to $\mathrm{ET}_{0}\left(G_{\mathrm{vSH}}\right)$ ranged from-8.4\% to $0.2 \%$ (Figure 5(c)). $G_{\mathrm{vSH}}$ was above 0 in only one site. The spatial distribution of $G_{\mathrm{vSH}}$ showed a downward trend from north to south. The attribution rate of wind speed to $\mathrm{ET}_{0}\left(G_{\mathrm{vWS}}\right)$ ranged from-19.1\% to $4.9 \%$ (Figure 5(d)). The highest absolute value of $G_{\mathrm{vWs}}$ was in Beijing and Tianjin.

The attribution rate of air temperature and relative humidity to $\mathrm{ET}_{0}$ was positive, which indicated that $\mathrm{ET}_{0}$ increased with an increase in these two climate factors. However, the mechanisms of $G_{\mathrm{vT}}$ and $G_{\mathrm{vRH}}$ were different. $G_{\mathrm{vT}}$ was positive when the sensitivity coefficient was positive and the tendency rate $\left(0.24^{\circ} \mathrm{C}\right.$ decade $\left.^{-1}\right)$ of air temperature increased (Figure 6(a)). $G_{\mathrm{vRH}}$ was positive when the sensitivity coefficient was negative and the tendency rate 


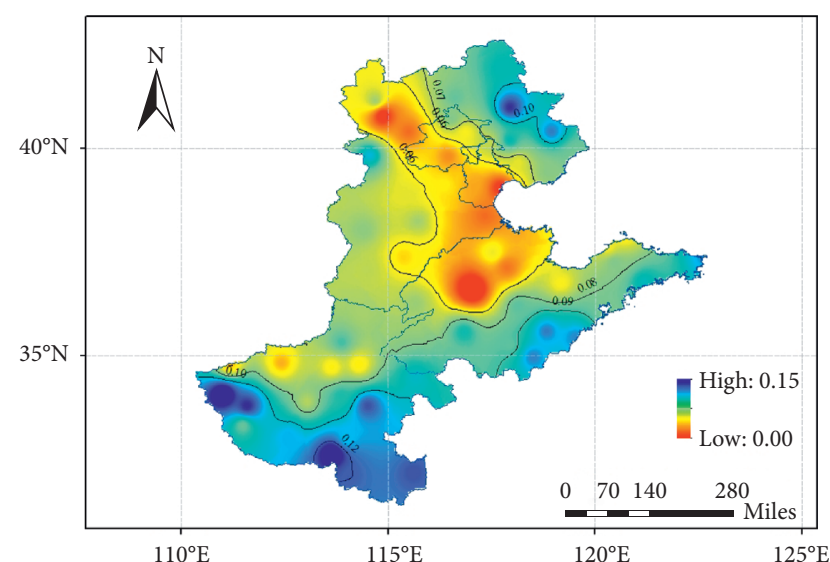

(a)

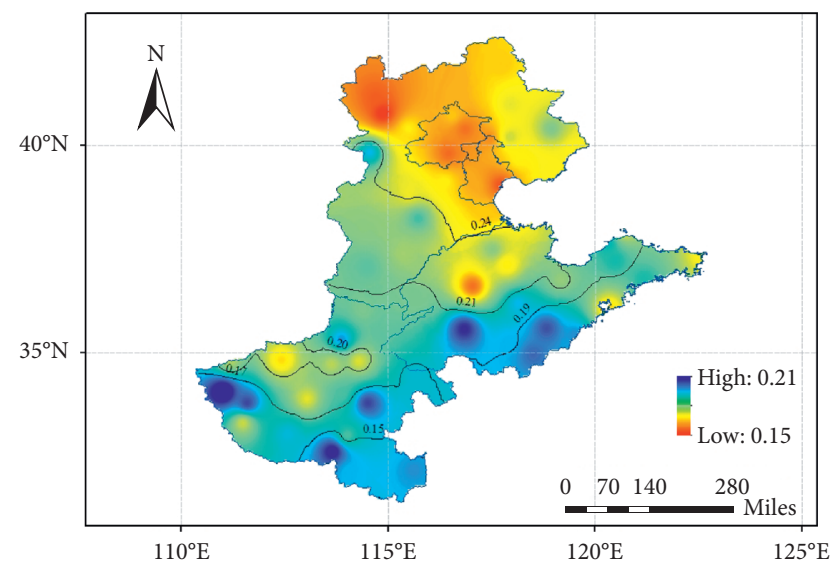

(c)

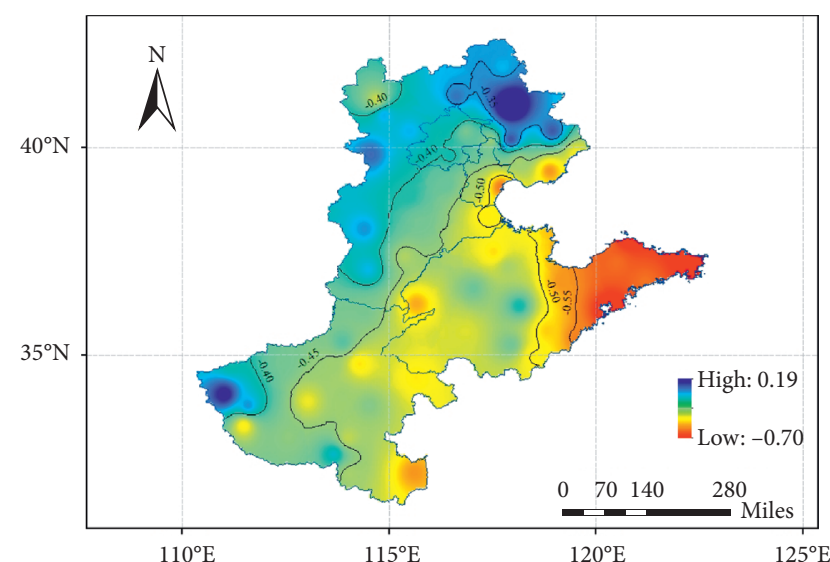

(b)

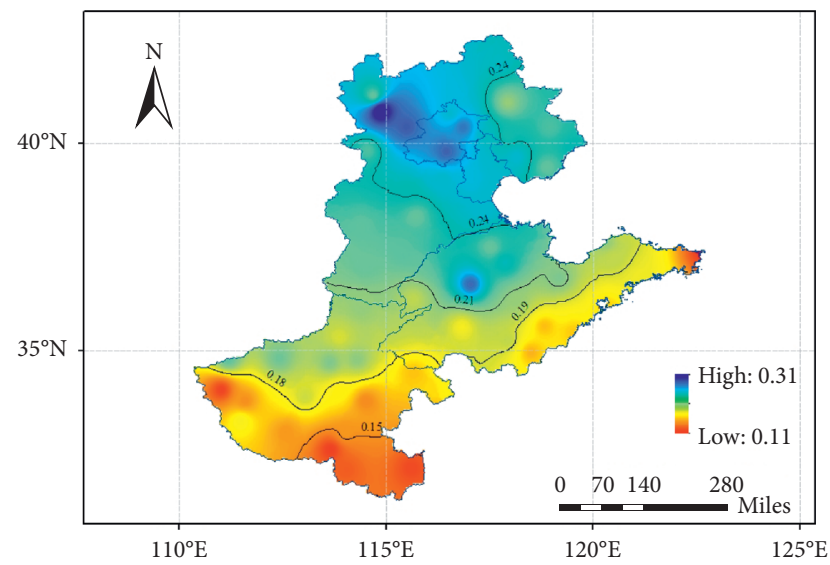

(d)

FIgURE 4: Spatial distribution of sensitivity coefficient of the main meteorological factors affecting ET $_{0}$ from 1961 to 2014 . (a) Temperature. (b) Relative humidity. (c) Sunshine hours. (d) Wind speed.

$\left(0.44\right.$ decade $\left.^{-1}\right)$ of relative humidity decreased (Figure 6(c)). The attribution rate of sunshine hours and wind speed was negative, which indicated that the change in the two climate factors decreased $\mathrm{ET}_{0}$. The attribution rate of climate factor to $\mathrm{ET}_{0}$ was in the following order: wind speed > sunshine hour $>$ relative humidity $>$ air temperature.

\section{Discussion}

The change in climate types was due to the sensitivity to various meteorological variables and their attribution to $\mathrm{ET}_{0}$ in the $\mathrm{NCP} . \mathrm{ET}_{0}$ was most sensitive to relative humidity, which had a negative effect. This was consistent with the study by $\mathrm{Hu}$ et al. [28] in Northeast China. The factor that impacted $\mathrm{ET}_{0}$ significantly varied depending on the location. Huo et al. [3] indicated that $\mathrm{ET}_{0}$ was very sensitive to $2 \mathrm{~m}$ wind speed and relative humidity in Northwest China. In southern Spain, $\mathrm{ET}_{0}$ was sensitive to air temperature and radiation in the warmer season and to $2 \mathrm{~m}$ wind speed in cooler seasons [29]. In Australia, temperature was found to be the most important factor for $\mathrm{ET}_{0}$, but the second-most important factors differed between dry and humid catchments [30]. Yang et al. [31] showed that the sensitivity of $\mathrm{ET}_{0}$ to climate factors varied from low elevations to high elevations. The sensitivity of $\mathrm{ET}_{0}$ to climate factors is regional variation because climate conditions and climate factors differ with regional variation [30, 31]. In this study, wind speed reduction was the main reason for the decline in $\mathrm{ET}_{0}$ from 1961 to 2014. However, the climate tendency rate was low and resulted in a relatively low attribution rate.

In general, warm climates led to an increase in evaporation and evapotranspiration. However, the observation of pan evaporation rate has been declined in most parts of the world in the past several decades $[8,9,32,33]$, which is called the pan evaporation paradox phenomenon [34]. Also, those only considered the influence of air temperature on $\mathrm{ET}_{0}$, without considering other meteorological factors, e.g., wind speed, relative humidity, and sunshine hours. It revealed significant increasing trends in $\mathrm{ET}_{0}(P=0.1)$ during 1961-1990 over the entire West African region [35]. Although the air temperature significantly increased at the rate of $0.24^{\circ} \mathrm{C}$ decade $^{-1}$, the effect of decrease in wind speed and sunshine hours was greater than that of the increase in air temperature, which led to a significant decline of $\mathrm{ET}_{0}$ in the NCP. This pattern of variations is in agreement with the findings of Dinpashoh et al. [36] in North-West Iran where most of the stations selected ( $86 \%$ of the sites) also showed increasing trends in $\mathrm{ET}_{0}$ between 1997 and 2016. However, Hou et al. [37] revealed that temperature was the key variable 


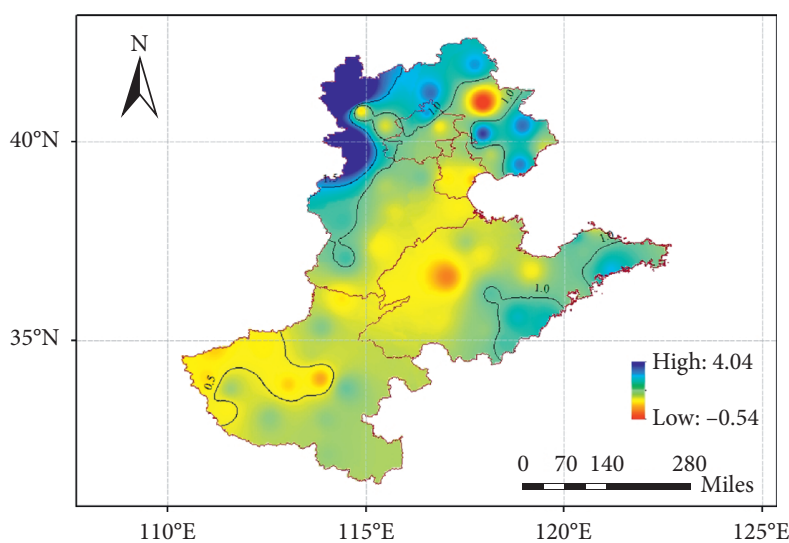

(a)

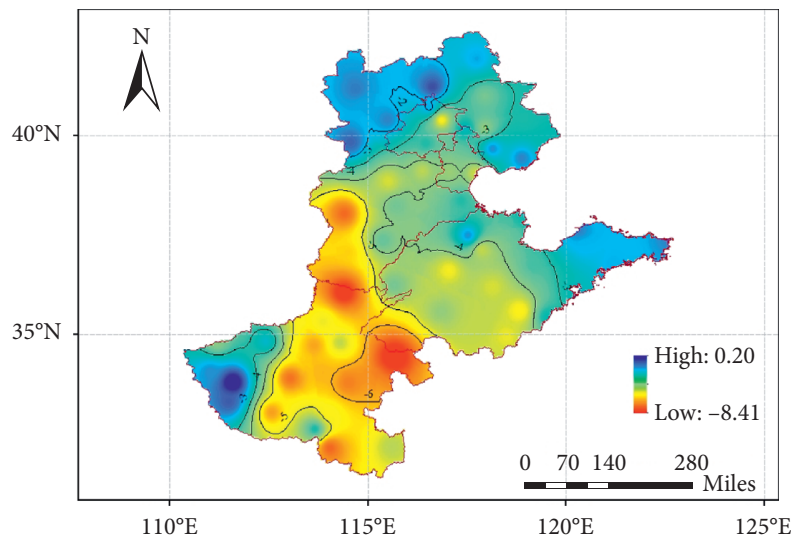

(c)

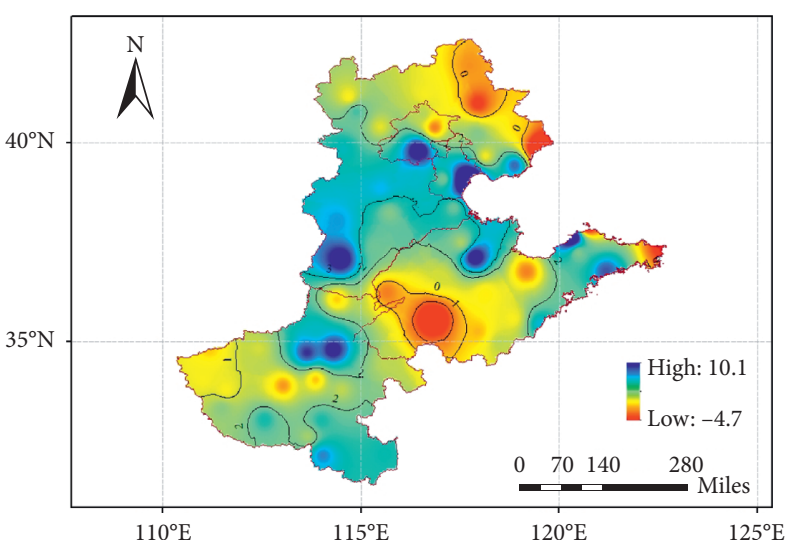

(b)

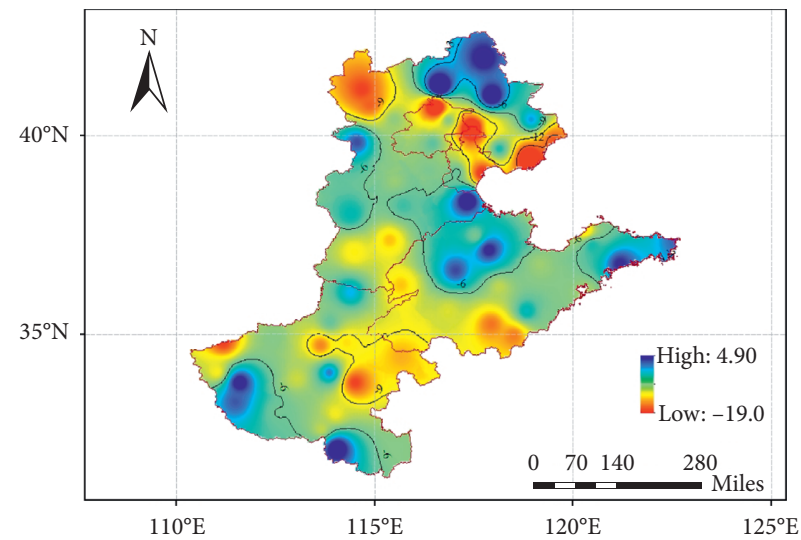

(d)

FIgURE 5: Spatial distribution of attribution rate to $\mathrm{ET}_{0}$ of the main meteorological elements from 1961 to 2014. (a) Temperature. (b) Relative humidity. (c) Sunshine hours. (d) Wind speed.
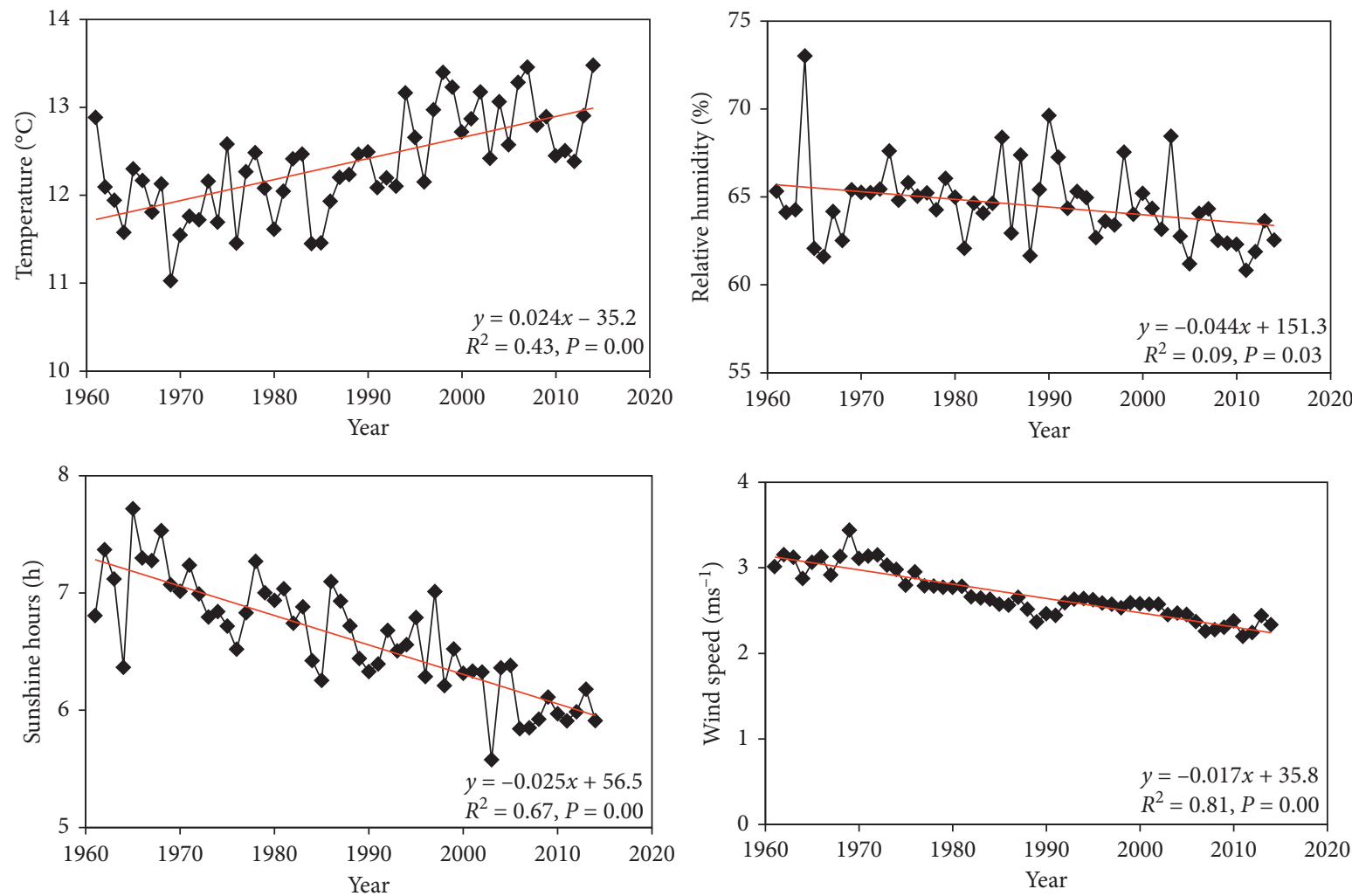

FIGURE 6: Tendency rate of temperature (a), relative humidity (b), sunshine hours (c), and wind speed (d) from 1961 to 2014 in the NCP. 


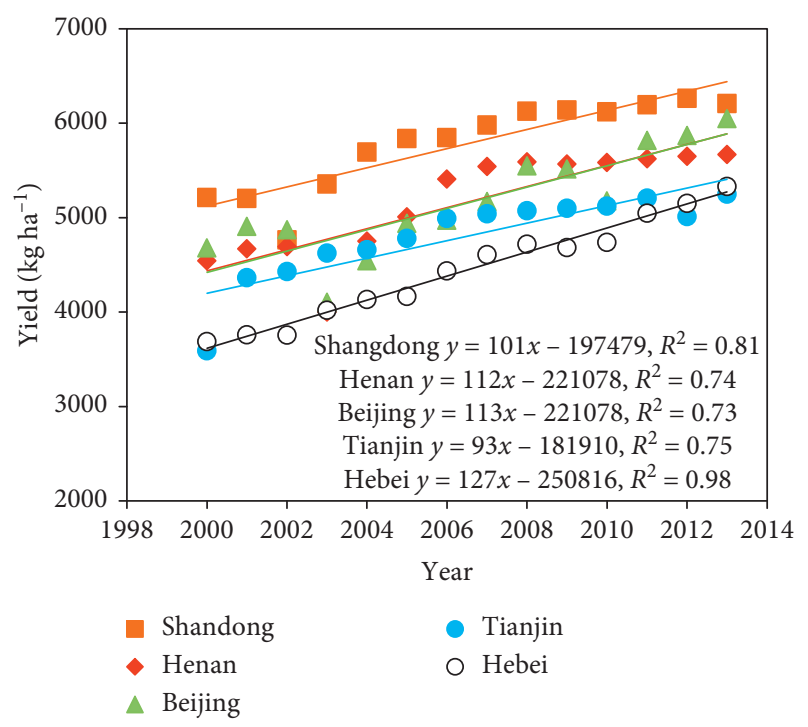

Figure 7: Crop yield from 2000 to 2013.

TABle 3: The annual humidity index $(K)$ from 1961 to 2014 in each region.

\begin{tabular}{lccccc}
\hline Sites & Shandong & Henan & Beijing & Tianjin & Hebei \\
$K$-value & 0.70 & 0.77 & 0.54 & 0.54 & 0.53 \\
\hline
\end{tabular}

contributing to increasing $\mathrm{ET}_{0}$ due to its sensitivity to $\mathrm{ET}_{0}$ and the significant increase trend.

Agriculture accounts for at least $90 \%$ of the total water use in the arid and semiarid regions [38]. An important way to alleviate water stress is to improve agricultural water management. Comprehensively understanding an agrohydrological process lays a foundation for minimizing agricultural water use. In the presence of a shallow water table, groundwater provides an important source for crop water use in arid and semiarid regions $[39,40]$, which impact crop productive. Climate type depended on the rate of change of precipitation and $\mathrm{ET}_{0}$. The important issue involves the evaluation of drought impacts on agriculture. Crop yields and drought occurrence statistics are closely related [42, 42], but consistency analysis of drought trends derived from humidity index and agricultural drought survey is sparse. Crop yield increased significantly $(P \leq 0.001)$ in the study area (Figure 7 ), in accordance with $K$ in each area. The crop yield was greater in Shandong and Henan province, with a $K$ of 0.70 and 0.77 , compared with that in Tianjin, Beijing, and Hebei (Table 3 ). The lowest $K(0.53)$ was in Hebei province, along with the lowest crop yield. Therefore, regional water balance should be considered and drought or flood risk might be reduced in these areas. China has investigated agricultural drought area for decades, so it is important to investigate the degree that $K$ and $\mathrm{ET}_{0}$ with agricultural drought surveys, especially in their climatic trends.

\section{Conclusions}

The NCP has experienced a semiarid to humid climate from north to south based on the humidity index due to the slight change in precipitation and the significant decline of $\mathrm{ET}_{0}$ on annual and spatial scales. In the study region, $71.0 \%$ of the sites showed a "pan evaporation paradox" phenomenon. $\mathrm{ET}_{0}$ was the most sensitive to relative humidity, particularly in East Shandong, followed by wind speed. The dominant cause of $\mathrm{ET}_{0}$ decline was wind speed, with the highest attribution rates, particularly in Beijing and Tianjin. The higher the humidity index in Shandong and Henan province was, the higher the crop yield was. The lower the humidity index in Hebei province was, the lower the crop yield was. It is necessary to analyze the influence of $\mathrm{ET}_{0}$ on crop yield at various crop growth stages.

\section{Data Availability}

The data used to support the findings of this study have been deposited in the 3691421data-2019.xls repository and are included within the article.

\section{Disclosure}

The first author is Wanlin Dong.

\section{Conflicts of Interest}

The authors declare that there are no conflicts of interest regarding the publication of this paper.

\section{Acknowledgments}

This research was supported by The National Key Research and Development Program of China (2017YFC0503805 and 2017YFD0300304).

\section{References}

[1] IPCC, Climate Change 2013: The Physical Science Basis. Contribution of Working Group I to the Fifth Assessment Report of the Intergovernmental Panel on Climate Change, Cambridge University Press, Cambridge, UK, 2013. 
[2] Q. Zhang, C. Xu, and Z. Zhang, "Observed changes of drought/wetness episodes in the Pearl River basin, China, using the standardized precipitation index and aridity index," Theoretical and Applied Climatology, vol. 98, no. 1-2, pp. 89-99, 2009.

[3] Z. Huo, X. Dai, S. Feng, S. Kang, and G. Huang, "Effect of climate change on reference evapotranspiration and aridity index in arid region of China," Journal of Hydrology, vol. 492, pp. 24-34, 2013.

[4] H. L. Penman, "Natural evaporation from open water, bare soil and grass," Proceedings of the Royal Society of London. Series A. Mathematical and Physical Sciences, vol. 193, pp. 120-145, 1948.

[5] N. Chattopadhyay and M. Hulme, "Evaporation and potential evapotranspiration in India under conditions of recent and future climate change," Agricultural and Forest Meteorology, vol. 87, no. 1, pp. 55-73, 1997.

[6] M. Gangopadhyay, V. A. Uryvaev, M. H. Oman, T. J. Nordenson, and G. E. Harbeck, Measurement and Estimation of Evaporation and Evapotranspiration, P. Govinda Rao, Ed., World Meteorological Organization, Geneva, Switzerland, 1966.

[7] J.-P. Lhomme, "Towards a rational definition of potential evaporation," Hydrology and Earth System Sciences, vol. 1, no. 2, pp. 257-264, 1997.

[8] S. Irmak, I. Kabenge, K. E. Skaggs, and D. Mutiibwa, "Trend and magnitude of changes in climate variables and reference evapotranspiration over 116-yr period in the Platte River Basin, central Nebraska-USA," Journal of Hydrology, vol. 420421, pp. 228-244, 2012.

[9] T. C. Peterson, V. S. Golubev, and P. Y. Groisman, "Evaporation losing its strength," Nature, vol. 377, no. 6551, pp. 687-688, 1995.

[10] S. Sun, H. Chen, G. Wang et al., "Shift in potential evapotranspiration and its implications for dryness/wetness over Southwest China," Journal of Geophysical Research: Atmospheres, vol. 121, no. 16, pp. 9342-9355, 2016.

[11] S. Lavergne, N. Mouquet, W. Thuiller, and O. Ronce, "Biodiversity and climate change: integrating evolutionary and ecological responses of species and communities," Annual Review of Ecology, Evolution, and Systematics, vol. 41, no. 1, pp. 321-350, 2010.

[12] K. E. McCluney, J. Belnap, S. L. Collins et al., "Shifting species interactions in terrestrial dryland ecosystems under altered water availability and climate change," Biological Reviews, vol. 87, no. 3, pp. 563-582, 2012.

[13] K. Zhang, S. Pan, W. Zhang et al., "Influence of climate change on reference evapotranspiration and aridity index and their temporal-spatial variations in the Yellow River Basin, China, from 1961 to 2012," Quaternary International, vol. 380-381, pp. 75-82, 2015.

[14] J. Doorenbos, Guidelines For Predicting Crop Water Requirements, FAO Irrigation Drainage, Rome, Italy, 1977.

[15] W. Shuttleworth and J. Wallace, "Calculating the water requirements of irrigated crops in Australia using the MattShuttleworth approach," Transactions of the ASABE, vol. 52, no. 6, pp. 1895-1906, 2009.

[16] P. Frich, L. V. Alexander, P. Della-Marta et al., "Observed coherent changes in climatic extremes during the second half of the twentieth century," Climate Research, vol. 19, pp. 193-212, 2002.

[17] Z. Li, Y. He, C. Wang et al., "Changes of daily climate extremes in southwestern China during 1961-2008," Global and Planetary Change, vol. 80-81, pp. 255-272, 2012.
[18] Z. Li, Z. Ouyang, X. Liu, and C. Hu, "Scientific basic for constructing the "Bohai Sea Grannry"-demands, potential and approaches," Chinese Science Bulletin, vol. 26, pp. 371374, 2011.

[19] D. B. Lobell, M. B. Burke, C. Tebaldi, M. D. Mastrandrea, W. P. Falcon, and R. L. Naylor, "Prioritizing climate change adaptation needs for food security in 2030," Science, vol. 319, no. 5863, pp. 607-610, 2008.

[20] F. Tao, M. Yokozawa, Y. Hayashi, and E. Lin, "Future climate change, the agricultural water cycle, and agricultural production in China," Agriculture, Ecosystems \& Environment, vol. 95, no. 1, pp. 203-215, 2003.

[21] F. Tao and Z. Zhang, "Climate change, wheat productivity and water use in the North China Plain: A new super-ensemblebased probabilistic projection, wheat productivity and water use in the North China Plain: a new super-ensemble-based probabilistic projection," Agricultural and Forest Meteorology, vol. 170, pp. 146-165, 2013.

[22] H. Bergamaschi, G. A. Dalmago, J. I. Bergonci et al., "Distribuição hídrica no período crítico do milho e produção de grãos," Pesquisa Agropecuária Brasileira, vol. 39, no. 9, pp. 831-839, 2004.

[23] G. Yan, Z. Yao, X. Zheng, and C. Liu, "Characteristics of annual nitrous and nitric oxide emissions from major cereal crops in the North China Plain under alternative fertilizer management," Agriculture, Ecosystems \& Environment, vol. 207, pp. 67-78, 2015.

[24] R. G. Allen, L. S. Pereira, D. Raes, and M. Smith, Crop Evapotranspiration Guidelines for Computing Crop Water Requirements, FAO Irrigation and Drainage, Rome, Italy, 1998.

[25] S. Shen, F. Zhang, and Q. Sheng, "Spatio-temporal changes of wetness index in China from 1975 to 2004," Transactions of the CSAE, vol. 25, pp. 11-15, 2009, In Chinese.

[26] L. Gong, C. Xu, D. Chen, S. Halldin, and Y. D. Chen, "Sensitivity of the Penman-Monteith reference evapotranspiration to key climatic variables in the Changjiang (Yangtze River) basin," Journal of Hydrology, vol. 329, no. 3-4, pp. 620-629, 2006.

[27] K. Beven, "A sensitivity analysis of the Penman-Monteith actual evapotranspiration estimates," Journal of Hydrology, vol. 44, no. 3-4, pp. 169-190, 1979.

[28] Q. Hu, F. Pan, X. Pan et al., "Dry-wet variations and cause analysis in Northeast China at multi-time scales," Theoretical and Applied Climatology, vol. 133, p. 775, 2016.

[29] J. Estévez, P. Gavilán, and J. Berengena, "Sensitivity analysis of a Penman-Monteith type equation to estimate reference evapotranspiration in southern Spain," Hydrological Processes, vol. 23, no. 23, pp. 3342-3353, 2009.

[30] D. Guo, S. Westra, and H. R. Maier, "Sensitivity of potential evapotranspiration to changes in climate variables for different Australian climatic zones," Hydrology and Earth System Sciences, vol. 21, no. 4, pp. 2107-2126, 2017.

[31] Y. Yang, R. Chen, Y. Song, C. Han, J. Liu, and Z. Liu, "Sensitivity of potential evapotranspiration to meteorological factors and their elevational gradients in the Qilian Mountains, Northwestern China," Journal of Hydrology, vol. 568, pp. 147-159, 2019.

[32] H. Tabari and P. Hosseinzadeh Talaee, "Sensitivity of evapotranspiration to climatic change in different climates," Global and Planetary Change, vol. 115, pp. 16-23, 2014.

[33] M. Garcia, D. Raes, R. Allen, and C. Herbas, "Dynamics of reference evapotranspiration in the Bolivian highlands 
(Altiplano)," Agricultural and Forest Meteorology, vol. 125, no. 1-2, pp. 67-82, 2004.

[34] L. R. Michael and D. F. Graham, "Changes in Australian pan evaporation from 1970 to 2002," International Journal of Climatology, vol. 24, pp. 1077-1090, 2004.

[35] M. L. Roderick and G. D. Farquhar, "The cause of decreased pan evaporation over the past 50 years," Science, vol. 298, no. 298, pp. 1410-1, 2002.

[36] O. E. Abiye, O. J. Matthew, L. A. Sunmonu, and O. A. Babatunde, "Potential evapotranspiration trends in West Africa from 1906 to 2015," SN Applied Sciences, vol. 1, pp. 1434-1456, 2019.

[37] Y. Dinpashoh, S. Jahanbakhsh-Asl, A. A. Rasouli, M. Foroughi, and V. P. Singh, "Impact of climate change on potential evapotranspiration (case study: west and NW of Iran)," Theoretical and Applied Climatology, vol. 136, no. 1-2, pp. 185-201, 2019.

[38] L. Hou, B. X. Hu, H. Li, and L. Wan, "Potential impacts of climate variation on potato field evapotranspiration: field experiment and numerical simulation of potato water use in an arid site," Journal of Geophysical Research: Atmospheres, vol. 123 , no. 18 , pp. 202-10, 2018.

[39] N. Whittlesey, "Improving irrigation efficiency through technology adoption: when will it conserve water?" Developments in Water Science, vol. 50, no. 3, pp. 53-62, 2003.

[40] S. Satchithanantham, V. Krahn, R. Sri Ranjan, and S. Sager, "Shallow groundwater uptake and irrigation water redistribution within the potato root zone," Agricultural Water Management, vol. 132, pp. 101-110, 2014.

[41] Y. Zhou, J. Wenninger, Z. Yang et al., "Groundwater\&ndash; surface water interactions, vegetation dependencies and implications for water resources management in the semi-arid Hailiutu River catchment, China \&ndash; a synthesis," $\mathrm{Hy}$ drology and Earth System Sciences, vol. 17, no. 7, pp. 24352447, 2013.

[42] C. Yu, C. Li, Q. Xin et al., "Dynamic assessment of the impact of drought on agricultural yield and scale-dependent return periods over large geographic regions," Environmental Modelling and Software, vol. 62, pp. 454-464, 2014.

[43] M. Mkhabela, P. Bullock, M. Gervais, G. Finlay, and H. Sapirstein, "Assessing indicators of agricultural drought impacts on spring wheat yield and quality on the Canadian prairies," Agricultural and Forest Meteorology, vol. 150, no. 3, pp. 399-410, 2010. 